\title{
1. Introduction: A look at social problems in Southern Europe from the south
}

\author{
Francisco Entrena-Durán, Rosa M. \\ Soriano-Miras and Ricardo Duque-Calvache
}

Social problems are socially constructed, although this does not mean that they are mere constructs or imaginaries, only existing in the minds of the social subjects that produce, perceive or live them. Although it is essential to consider subjective imaginaries (more or less incorporated by individual or group social subjects) regarding social problems to understand them, they clearly have a real basis, as their existence can be verified through empirical study of the processes through which they become subjectively perceived objective realities (Frigerio, 1995), as well as through analysis of the socio-temporal contexts in which they emerge. To a great extent, we agree with Rubington and Weinberg (2010), who differentiate two constructionist perspectives in the analysis of social problems: on one hand, a strict constructionism, focused on the subjective definition of problems, and, on the other, a contextual constructionism, which also includes the context in which these problems are produced and reproduced as an essential factor that must be considered.

The subjective dimension of social problems, even if considered from the perspective of the strict constructionism that Rubington and Weinberg refer to, as a mere definition of such problems or a mental construction related to them, is as empirically verifiable and analyzable as is any objective dimension. This is because the subjective dimension can be objectified through the identification of the evaluations, representations and discourses constructed regarding specific social phenomena and circumstances that are perceived as social problems by some segment of the social subjects that voluntarily or involuntarily (or consciously or unconsciously, as well) produce and experience them (Blumer, 1971).

Thus, when we refer to the social construction of social problems, we do not understand this as if it is a mere elaboration of representations of these problems (the previously mentioned mental constructs or imaginaries), as if these problems only existed in ideas and through ideas that actors have 
constructed regarding themselves and the social world. Instead, we consider these representations and imaginaries as responses to processes of the production of social problems stricto sensu, as well as to mental processes through which individuals and groups construct objectifications of these social problems laden with meaning - that is, perceptions, explanations and discourses (Lorenc-Valcarce, 2005). In addition, at the same time that they construct and internalize these discourses, social subjects give meaning to social problems; they confer existence on them, contributing, in this way, to their construction, deconstruction and reconstruction (Pofhl, 1985; Spector and Kitsuse, 1977), as well as to their definition, evaluation and diagnosis, and, ultimately, to intervention.

Blumer (1971) explains that the process of collective definition in the formation of social problems passes through five phases: (1) the emergence of a social problem; (2) its legitimization; (3) mobilization of action in response; (4) the formation of an official plan of action; and (5) the empirical implementation of this plan. From this perspective, only certain social phenomena end up being constituted as social problems, as certain socioeconomic, political/ institutional and symbolic-cultural circumstances have to exist. These circumstances vary in each case, as the perspectives that social subjects develop regarding these problems are varying and diverse as well, oscillating between two extreme positions. One is represented by attitudes that tend toward the acceptance and legitimacy of a social problem as consubstantial to the social system, conceiving it as something natural and inherent within an order of things whose essential functioning logic will always generate social problems. Thus, the only solution is to better manage the social system so that the effects of its problems are minimized. At the other extreme are more critical attitudes, tending to delegitimize the social order, seeking its dismantling or transformation. The social order from this perspective is considered not as a natural or immutable state of things, but rather as a more or less transitory situation corresponding to specific socio-historical circumstances that, for those that share this perspective, can and should be changed.

Independently of their greater or lesser degree of closeness to one of these two extremes, the fact is that the assessments, constructions and perceptions of social problems are sustained by the construction and reconstruction of a series of symbolic-cultural frames that confer legitimacy on these assessments. These frames, in turn, provide meaning to the practices and attitudes of the social subjects that live and face these social problems.

It is the subjects themselves that produce social problems; they also define, interpret, perceive and live them and have the capacity to address them and intervene in them. Intervention involves trying to modify or regulate the social order, social actions and the practices that generate social problems, which, in 
turn, often involves bringing about the partial, structural or systemic changes (that is, in social structures) necessary to overcome them.

The fact that social problems are socially constructed means that they can be both the expected or unexpected (in the majority of cases it is the latter) results of specific practices or actions on the part of individual or group social subjects. These practices or actions take place within specific processes or social spheres; in other words, they do not take place in a decontextualized manner, but rather happen in particular spatial-temporal contexts.

This book addresses a series of social problems that have been produced and reproduced (constructed and reconstructed) in the current context of Southern European societies. These problems are examined comparing the four Southern European countries included in this study: Portugal, Spain, Italy and Greece. The primary reason for the focus on these four countries is that they are generally considered to constitute a group with specific and shared social problems, as well as with forms of addressing said problems that differ from the way they are addressed by their northern counterparts. Thus, while Portugal, Spain, Italy and Greece reveal a remarkable diversity of historical traditions and socioeconomic and political circumstances, at the same time, they share a common series of characteristics that make it possible to group them within the denomination "Southern European countries". Among these characteristics, their accentuated cultural and social similarities can be highlighted, which result from the fact that they are all part of a Greco-Roman cultural epistemology that was essential to the genesis of the Western world. Likewise, all these countries share common economic characteristics (for instance, tourism has a significant weight in the gross domestic product (GDP) of all four countries), as well as political contexts with significant similarities; for example, Portugal, Greece and Spain constituted the last dictatorships in western Europe, all of which ended at the beginning of the 1970s (Poulantzas, 1976).

In addition, these countries occupy a common geostrategic position that is growing in importance in the current scenario of the European Union (EU) and the world. Thus, it is no coincidence that a vast majority of the territory of these countries is open to the sea, that is, to the Atlantic Ocean and, above all, the Mediterranean. In particular, regarding the Mediterranean and its surrounding societies, this is an environment that, since the height of classical Greek and Roman societies and for centuries, was highly heterogeneous, decentralized and contradictory. For example, in this environment diverse Mediterranean civilizations existed and related (harmoniously or in conflict) in the sixteenth century (Greek, Latin, Judaic, Islamic). They mutually interacted and traded (goods, symbols, ideas and persons), without losing their particular social and cultural traits (Braudel, 2001). Of course, at that time there existed wide cultural and spatial distances between these civilizations, which today 
have been drastically reduced as a consequence of the modern technologies of transport and mobility that have fostered current globalization processes, with the subsequent progressive interconnecting on a planetary scale that this has led to, and permitting what Harvey (1990, Part III) has conceptualized as the increasing compression of space and time. The latter refers to an ongoing change in the human experience of time and space that is grounded, above all, in the fact that the means of available mobility (the shift from horses and sail boats to current airplane travel) have reduced the time necessary to cross increasingly greater spaces. The magnitude of this compression of time and space, as well as the radical changes that this has generated in terms of human perception and experience, is a shared phenomenon around the world.

Specifically, regarding the Mediterranean Sea, this process can be clearly seen when, for example, we compare the situation that, according to Braudel (2001), existed in the sixteenth century (1551-1598) with the current situation. At that earlier time, crossing the sea from Constantinople to Alexandria took 15 days including stops, and eight days without any. In addition, crossing the sea in the direction of the meridians would take two weeks without stops and long journeys could take up to three months.

In contrast, the means of travel today makes these journeys a question of hours; in other words, we do them at speeds and times that were unimaginable before. However, although transport and the means of communication make it possible for Mediterranean countries to be closer and more connected than ever before, the socioeconomic and cultural differences between one side of the sea and the other seem to have, paradoxically, increased due to the different political-institutional circumstances in each place. On the north-south axis, the incorporation of Southern European countries into the EU has led to those countries looking northward, in a certain way turning their backs on their secular historical trajectory. Thus, integration in the powerful regional block of the EU has clearly had advantages; but Greece, Italy, Portugal and Spain have also been placed in peripheral positions with respect to the power of the Paris-Berlin axis. This subordination to the interests and strategic aims of the countries of the central and northern EU is a common element for these southern countries and affects, as would be expected, the way in which they address their social problems. The EU has contributed to the advance of many political and socioeconomic agendas, but at the same time it may have created the false impression that there is homogeneity among its different member states. Recent financial and political tensions have revealed lines of divergence, opposing sides inside the EU, not based on political alignments, but connected to a wider regional context. Given this background, comparative studies like the ones in this collective book on social problems in Europe's southern countries allow the authors to focus attention on the specific European contexts where social problems emerge and are addressed. 
For all these reasons, this study of social problems in Southern European countries within their own context and taking into account the particularities of that context is very necessary. Therefore, collectively written books like this one, in which the social problems of these countries are approached from a comparative perspective, are very timely. In addition, this is not only a book about Southern Europe, but one written within Southern Europe, of relevance in the construction and perception of the social problems addressed. To find and coordinate the work of authors from the four countries considered here has involved significant effort, but we believe it was crucial to reach an adequate understanding of the reality of Southern Europe from within. This book is organized into three thematic blocks.

The first block in Part I, "Prejudice, discrimination and identity", addresses social problems integrated in the collective imaginary, but that generate real consequences in the lives of the population. In Chapter 2, "Social unrest in southern European societies: Spain, Portugal, Italy and Greece", Julio Iglesias de Ussel, José Manuel García Moreno and Fernando Sadio Ramos analyze how difficult socioeconomic and political circumstances, joined with other cultural factors, can lead to social unrest. The authors differentiate between social problems in a state of hibernation or latent state, and those in an agitated state that affect social stability. Along the same lines, but with a different focus, Esther Igorra Canillas, Inam Benali Tahiri and Antonio Trinidad Requena address the effects of globalization and integration on supranational structures in their chapter, "Citizens' trust in institutions in southern Europe: the cases of Spain, Greece, Italy and Portugal", as well as the appearance of distrust as a reaction to these general changes. However, distrust is very closely related to the rise of so-called post-truth, an issue addressed by Pablo Galindo-Calvo, Beatriz Jiménez-Roger, Francisco Javier Cantón-Correa and Maria do Nascimento Esteves-Mateus in their chapter on "Islamophobia in southern Europe: the cases of Greece, Spain, Italy and Portugal", in which they address this issue of great social and media importance. The authors focus their attention on both the media and the reactions and dynamics manifested in social networks.

The second block in Part II, "The social problems in the life course", descends from the macro level in which the initial studies were framed, to a meso or even micro level, placing the focus on individuals and the social groups directly affected by the social problems examined, and their connection to changes associated with the life course. First, Chapter 5, "Childhood obesity as a social problem: prevention policies in Spain and Portugal", combines an analysis of dietary changes linked to globalization with policies for prevention and social intervention. Juan Miguel Valdera-Gil, Francisco Entrena-Durán and Philippe Cardon conclude that childhood obesity is linked to social inequality, an issue that connects with the second study in Part II, written by Félix 
Fernández Castaño, María Jesús Santiago Segura, Alessandro Gentile and Luis Fernando López García. These authors analyze "Early school leaving as a social problem in Spain, Italy and Greece" using statistics on abandonment and examining measures taken to confront this problem, which can seriously damage the future possibilities of children and adolescents to reach important goals. One of these goals can be leaving the family home, an issue examined in Chapter 7, "Fear of flying? Leaving home late for young people in the south" by Nayla Fuster, Sonia Bertolini and Ricardo Duque-Calvache. The authors study the role of the family, cultural perceptions and the effects of the economic crisis that began in 2008 on the decision to enter the adult world, a decision which is being made increasingly late. Lastly, and focusing on the last stages of the life course, Juan López Doblas, Isabel Palomares-Linares and Mariano Sánchez Martínez in "Loneliness in older adults: a comparative study in four southern European countries", warn of the existence of certain diverging patterns between the countries of Southern Europe and certain commonalities with trends in the countries of central and northern Europe, reinforcing the idea of the need to question the supposed homogeneity of regional blocks, in this case, the block of Southern European countries studied in this book.

The third part of this book, "Spatial, productive and consumer reconfigurations", includes a series of chapters that focus on social problems linked to transformations in the socioeconomic structure, their geographic impacts and their implications for the environment. First, Rafael Martínez Martín, Teresa Rodríguez Molina and Antonio Martínez López argue in Chapter 9, "Unemployment as a social problem in southern countries in the EU: analysis of Spain, Greece, Italy and Portugal", that unemployment can be considered one of the most important social problems facing young people in those countries, as well as an endemic characteristic of their productive systems. "The deindustrialization of textiles in southern Europe: from the perspective of gender”, by Rocío Fajardo Fernández, Edmé Domínguez-Reyes and Cristina Fuentes-Lara, examines the transformation of this productive sector from a gender perspective. Although gender is a transversal issue that impacts all of the problems addressed in this book, it also merits specific attention.

Systemic changes are not limited to the productive sphere, but also affect consumers and their purchasing decisions. The growing spread of e-commerce is generating new opportunities linked to the rupture of physical space, but not all the consequences of these changes are positive, as pointed out by the authors Rosa Soriano-Miras, Francisco Barros Rodríguez, Basem Mahmud and Simona Gozzo in their chapter, "The world in one click: the digital divide associated with e-commerce in southern Europe". From a more demographic perspective, but closely related to questions of land-use, Tamara Álvarez Lorente, José Luís Sousa Soares de Oliveira Braga and Antonio Barros Cardoso analyze "The social problem of rural depopulation in Spain and 
Portugal". Population loss can threaten social cohesion and the future socioeconomic development of rural areas. While rural towns lose inhabitants, cities grow, but face their own set of problems. Isabel Palomares-Linares, Henar Baldán, José Manuel Torrado and Joaquín Susino look at spatial segregation in their chapter "Making place for 'urban segregation matters' in four southern European countries: a literature review". The separation of urban populations into neighborhoods is closely related to social segregation and the reproduction of social problems such as poverty and exclusion. Lastly, Adolfo Torres-Rodríguez, Juan Francisco Bejarano-Bella, Roser Manzanera-Ruiz, Luigi Pellizzoni and Claudio Marciano present "A critical analysis of the circular economy in southern Europe: an innovative proposal for addressing environmental degradation and the sustainability of life". Environmental degradation, perceived by broad segments of the population as a global problem, is made glocal in specific local settings. This chapter, focused on our four Southern European countries, contributes new ideas of use in analyzing and facing the problems of environmental decay and sustainability.

To sum up, the reader has a book that has brought together specialists from different parts of the EU and one with a diverse theoretical/analytical focus regarding the social problems it examines. However, independent of their different perspectives, all these specialists are united in their concerns regarding social problems in Southern European societies. In this regard, we have tried to include in our study a wide range of contributions that, in our opinion, take account of the most important social problems experienced by Southern European societies. However, we are fully aware that the range of social problems analyzed here does not encompass (nor have we intended it to encompass) all of the existing social problems in Southern European countries. In any case, we hope that this book serves as a stimulus for the continuing development of social science research along these same lines, while also being useful to those with the authority to design and implement the public policies needed in Southern European countries to successfully address the challenges presented by the social problems they currently face.

\section{REFERENCES}

Blumer, H. (1971). Social problems as collective behavior. Social Problems, 18, 298-306. Doi: 10.2307/799797.

Braudel, F. (2001). El mediterráneo y el mundo mediterráneo en la época de Felipe II. Madrid: Fondo de Cultura Económica, 1949.

Frigerio, A. (1995). La construcción de los problemas sociales: cultura, política y movilización. Boletín de Lecturas de Sociales y Económicas, 6, 12-17.

Harvey, D. (1990). The condition of postmodernity: An enquiry into the origins of cultural change. Boston, MA: Blackwell. 
Lorenc-Valcarce, F. (2005). La sociología de los problemas públicos. Una perspectiva crítica para el estudio de las relaciones entre la sociedad y la política. Nómadas, $12(2), 141-150$.

Pofhl, S. (1985). Toward a sociological deconstruction of social problems. Social Problems, 32(3), 228-232. Doi: 10.2307/800681.

Poulantzas, N. (1976). La crisis de las dictaduras: Portugal, Grecia, España. Madrid: Siglo XXI.

Rubington, E. \& Weinberg, M. (Eds.). (2010). The study of social problems. New York: Oxford University Press.

Spector, M. \& Kitsuse, J.I. (1977). Constructing social problems. Menlo Park, CA: Cummings. 